OPEN ACCESS

Edited by:

Tong-Bao Liu,

Southwest University, China

Reviewed by:

Ling Lu,

Nanjing Normal University, China

Ence Yang,

Peking University, China

*Correspondence:

Chen Ding

dingchen@mail.neu.edu.cn

Tianshu Sun

sun_tianshu@163.com

${ }^{t}$ These authors have contributed equally to this work and share first authorship

Specialty section:

This article was submitted to

Fungal Pathogenesis,

a section of the journal

Frontiers in Cellular and

Infection Microbiology

Received: 11 September 2021

Accepted: 15 November 2021

Published: 02 December 2021

Citation:

Li Y, Li H, Sun T and

Ding C (2021) Pathogen-Host Interaction Repertoire at Proteome and Posttranslational Modification

Levels During Fungal Infections.

Front. Cell. Infect. Microbiol. 11:774340.

doi: 10.3389/fcimb.2021.774340

\section{Pathogen-Host Interaction Repertoire at Proteome and Posttranslational Modification Levels During Fungal Infections}

\author{
Yanjian $\mathrm{Li}^{1 \dagger}$, Hailong $\mathrm{Li}^{2 \dagger}$, Tianshu Sun ${ }^{3,4 *}$ and Chen Ding ${ }^{1 *}$ \\ ${ }^{1}$ College of Life and Health Sciences, Northeastern University, Shenyang, China, ${ }^{2}$ NHC Key Laboratory of AIDS Immunology \\ (China Medical University), National Clinical Research Center for Laboratory Medicine, The First Affiliated Hospital of China \\ Medical University, Shenyang, China, ${ }^{3}$ Medical Research Centre, State Key Laboratory of Complex Severe and Rare \\ Diseases, Peking Union Medical College Hospital, Chinese Academy of Medical Science, Beijing, China, ${ }^{4}$ Beijing Key \\ Laboratory for Mechanisms Research and Precision Diagnosis of Invasive Fungal Diseases, Beijing, China
}

Prevalence of fungal diseases has increased globally in recent years, which often associated with increased immunocompromised patients, aging populations, and the novel Coronavirus pandemic. Furthermore, due to the limitation of available antifungal agents mortality and morbidity rates of invasion fungal disease remain stubbornly high, and the emergence of multidrug-resistant fungi exacerbates the problem. Fungal pathogenicity and interactions between fungi and host have been the focus of many studies, as a result, lots of pathogenic mechanisms and fungal virulence factors have been identified. Mass spectrometry (MS)-based proteomics is a novel approach to better understand fungal pathogenicities and host-pathogen interactions at protein and protein posttranslational modification (PTM) levels. The approach has successfully elucidated interactions between pathogens and hosts by examining, for example, samples of fungal cells under different conditions, body fluids from infected patients, and exosomes. Many studies conclude that protein and PTM levels in both pathogens and hosts play important roles in progression of fungal diseases. This review summarizes mass spectrometry studies of protein and PTM levels from perspectives of both pathogens and hosts and provides an integrative conceptual outlook on fungal pathogenesis, antifungal agents development, and host-pathogen interactions.

Keywords: fungal pathogens, proteome, mass spectrometry, virulence factors, host-pathogen interaction, posttranslational modification

\section{INTRODUCTION}

Fungal pathogenic diseases that cause high mortality and morbidity are increasing in prevalence globally, coincident with accelerating numbers of patients with COVID-19, HIV infection, and organ transplants (Hurtado et al., 2019; Stone et al., 2019; Heard et al., 2020; Hoving et al., 2020; Song G. et al., 2020; Yoon et al., 2020; Rawson et al., 2021). Furthermore, invasive fungal infections 
are intractable because of long treatment cycles and high probability of relapse (Ecevit et al., 2006). Common human pathogenic fungi, including Candida albicans, Aspergillus fumigatus, and Cryptococcus neoformans, are opportunistic pathogens that are always associated with host immune status (Alhumaid et al., 2021; Pasquier et al., 2021; Singh et al., 2021). To invade a host and replicate and spread, pathogens need to obtain host resources, such as a carbon source, proteins, and lipids, and avoid or take advantage of host defense mechanisms. Pathogens have evolved a variety of virulence factors, such as biofilms, capsules, morphologic transformations, and kinase systems, to facilitate infection (Ding and Butler, 2007; Wang et al., 2012; Do et al., 2018; Suo et al., 2018; Lee et al., 2019; Vu et al., 2019). In response to fungal attack, hosts alter the microenvironment and activate the immune system by modifying body temperature, oxidation levels, and metal contents, limiting nutrients, and increasing levels of inflammatory factors and immune cells (Hu et al., 2008; Butler et al., 2009; Kronstad et al., 2011; Kronstad et al., 2012; Saikia et al., 2014; Rohatgi and Pirofski, 2015; Hole and Wormley, 2016; Ballou and Johnston, 2017; Hansakon et al., 2019; Sun et al., 2019).

Pathogens and hosts require rapid modulation of virulence and defense mechanisms, which is a conclusion validated by many different biological technologies (Butler et al., 2009; Kronstad et al., 2011; Kronstad et al., 2012). For example, alterations at the C. neoformans and host (mouse and Macaca fascicularis) axis were monitored with transcriptome technology (Li H. L. et al., 2019). Genes were expressed to counter fungal invasion that were involved in immune and inflammatory responses, osteoclastogenesis (in particular, osteoclastogenesisassociated gene (OC-STAMP)), and insulin signaling. The fungus responded rapidly by activating metal sequestration, dampening sugar metabolism, and changing cell morphology to increase its survival in the host (Li H. L. et al., 2019). However, important aspects of complex host-pathogen interactions are addressed differently by different techniques (Jacobsen et al., 2018; Li H. L. et al., 2019; Li et al., 2020).

Over past decades, application of MS-based proteomics has expanded rapidly, especially in studies of proteomes and posttranslational modifications (PTMs), such as acetylation, phosphorylation, succinylation, and crotonylation (Figure 1A) (Aggarwal et al., 2021). Application in studies of microbiological pathogenesis and interactions between pathogens and hosts has led to the discovery of many novel mechanisms of hostfungus interactions (Toor et al., 2018; Khan et al., 2019; Li Y. et al., 2019; Zamith-Miranda et al., 2019; Bruno et al., 2020; Machata et al., 2020; Thak et al., 2020; Zhou et al., 2021). Establishing connections between proteomic profiles and fungal infection processes is critical in characterizing disease pathophysiology, developing candidate therapies, and predicting clinical outcomes.

This review will focus on the applications of MS-based proteomics to examine protein and PTM levels from perspectives of both pathogens and hosts, give a comprehensive opinion and novel outlook on fungal pathogenesis, antifungal therapy, and host-pathogen interactions.

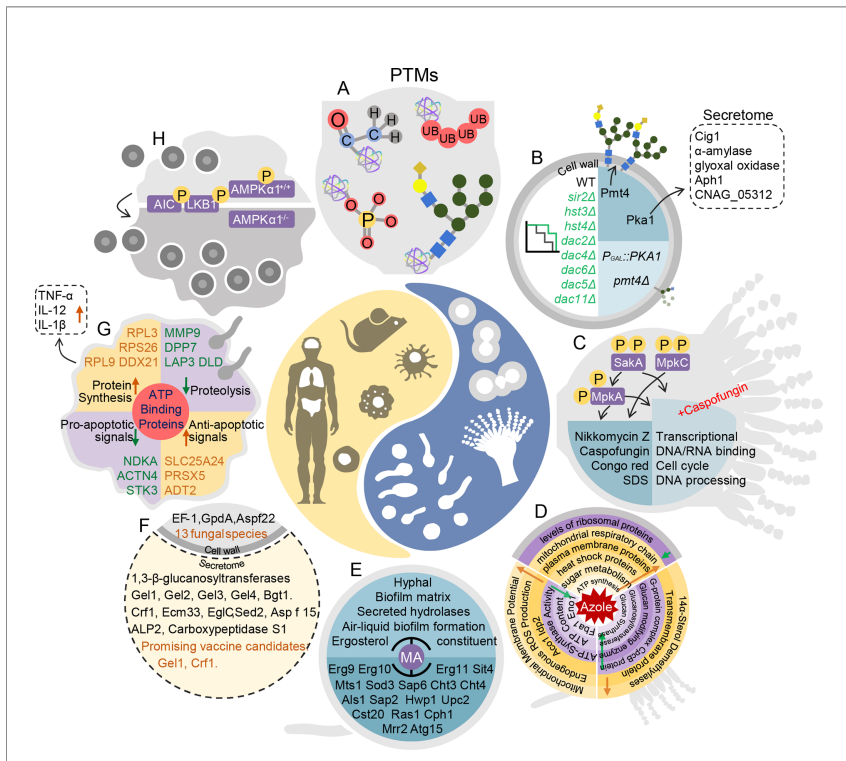

FIGURE 1 | Pathogen-host interaction repertoire at proteome and posttranslational modification levels during fungal infections. (A) Posttranslational modifications in fungal pathogenesis. (B) In Cryptococcus neoformans, deacetylases Sir2, Hst3, Hst4, Dac2, Dac6, Dac4, Dac5, and Dac11 are all essential for pathogenesis. Knockout of PMT4 decreases protein mannosylation inefficiency. In the PGAL 7::PKA1 strain, expression of 61 secretome proteins changes, including that of Cig1, $\alpha$-amylase, glyoxal oxidase, Aph1, and CNAG_05312. (C) In Aspergillus fumigatus, SakA ${ }^{\mathrm{HOG} 1}$, MpkC, and MpkA are phosphorylated. sakA $\Delta$ and $m p k C \Delta$ sak $A \Delta$ are more sensitive to caspofungin and nikkomycin Z, congo red, and sodium dodecyl sulfonate (SDS). In mpkA $\Delta$ and sakA $\Delta$ treated with high doses of caspofungin, decreases occur in DNARRA binding, cell cycle control, and DNA processing pathways. (D) Top: In response to fluconazole, in Cryptococcus neoformans, ribosomal proteins decrease and heat shock proteins, plasma membrane proteins, and proteins involved in glucose metabolism, ATP synthesis, and mitochondrial respiratory chains increase over time. Left: When Candida albicans is treated with fluconazole, mitochondrial membrane potential, endogenous reactive oxidative species production, and Aco1 Idp2 are up-regulated. Right: When Aspergillus fumigatus is exposed to itraconazole, $14 \alpha$-sterol demethylases and transmembrane proteins are up-regulated, and G-protein complex, glucan modifying enzyme, glucanosyltransferase, and glucan synthase are down-regulated. (E) In Candida albicans, MA inhibits hyphae, biofilm matrix, secreted hydrolases, air-liquid biofilm formation, and ergosterol constituents by regulating Erg9, Erg10, Erg11, Sit4, Mts1, Sod3, Sap6, Cht3, Cht4, Als1, Sap2, Hwp1, Upc2, Cst20, Ras1, Cph1, Mrr2, and Atg15. (F) In the intracellular proteome and secretome of 13 fungi, cell extracts consist of EF-1, GpdA, and Aspf22. Secretion consists of 1,3-beta glucanosyltransferases, including Gel1, Gel2, Gel3, Gel4, Bgt1, Crf1, Ecm33, EglC, Sed2, Asp f15, ALP2, and carboxypeptidase S1. Gel1 and Crf1 screen as promising vaccine candidates. (G) ATP-binding proteins are enriched in macrophages infected with Candida albicans. Anti-apoptotic proteins PRDX5, SLC25A24, and ADT2 increase, whereas pro-apoptotic proteins NDKA, ACTN4, and ST3 decrease. Ribosomal proteins RPL9, RPS26, and RPL3 increase. Proteolysis-associated proteins MMP9, DPP7, LAP3, and DLD decrease. In addition, secretion of TNF- $\alpha, I L-12$ and IL-1 $\beta$ increase. $(\mathbf{H})$ Deletion of AMPK $\alpha 1$ in monocytes leads to resistance to Cryptococcus neoformans colonization in mice.

\section{PROTEOMIC PROFILES OF FUNGAL PATHOGEN RESPONSES TO STRESS}

Proteomics can contribute to understanding variations in global protein expression in fungal pathogens under stress. Plasticity in fungal pathogen response to different host microenvironments is 
important for successful infection. Maintaining oxidative homeostasis is a critical strategy as fungal pathogens adapt to their hosts (Table 1). Aspergillus fumigatus tolerates hypoxic conditions in lung infections, and therefore, differentially expressed proteins under hypoxic treatment can reflect fungal virulence performance (Warn et al., 2004; Tarrand et al., 2005; Willger et al., 2008). Proteins involved in glycolysis, tricarboxylic acid(TCA) cycle, oxidative phosphorylation, ergosterol biosynthesis, metals metabolism, secondary metabolism, and generation of nitrosative stress are differentially expressed under hypoxic conditions in A. fumigatus (Vodisch et al., 2011; Barker et al., 2012). Metals are widely known to participate in stress resistance in fungi (Ding et al., 2011; Samanovic et al., 2012; Ding et al., 2013; Ding et al., 2014a; Ding et al., 2014b; Sun et al., 2014; Do et al., 2018; Li et al., 2019a). In A. fumigatus, additional oxidative stress response is related to iron availability (Kurucz et al., 2018). Furthermore, starvation and high concentrations of metal ions, such as iron and copper, are challenges from the natural environment and host (Ding et al., 2014a; Sun et al., 2014; Li et al., 2019b). In microsomal proteome analysis of A. fumigatus, 231 proteins were significantly differentially expressed between iron-rich and iron-depleted conditions, which included siderophore transporters, indicating that microsomal proteins were associated with iron-depleted conditions (Moloney et al., 2016). In another study, ironresponsive microsomal protein MirC was associated with maintenance of iron homeostasis in A. fumigatus, which was consistent with the increased abundance of siderophore biosynthetic enzymes in mirC $\Delta$ (Mulvihill et al., 2017). Protein phosphatase PpzA, an iron assimilation factor, influences the pathogenicity of $A$. fumigatus by reducing secondary metabolites under iron starvation (Manfiolli et al., 2017). To investigate iron homeostasis, proteomic analysis based on cross-linked tandem affinity purification coupled with MS was also performed in $C$. albicans, and Fra1, Bol2/Fra, Sfu1, and Hap43 were found to interact with iron homeostasis regulator monothiol glutaredoxin

TABLE 1 | Summary of proteomic studies in fungal pathogens.

\begin{tabular}{|c|c|c|}
\hline Functions & Pathogens & Description \\
\hline \multirow[t]{3}{*}{$\begin{array}{l}\text { Proteomic Profiles of } \\
\text { Fungal Pathogen } \\
\text { Responses to Stress }\end{array}$} & A. fumigatus & $\begin{array}{l}\text { Proteomic studies have found that some key pathways differ under } \\
\text { stresses, including hypoxic conditions, oxidative stress, iron-rich } \\
\text { conditions, iron-depleted conditions, and osmotic stress. }\end{array}$ \\
\hline & C. albicans & $\begin{array}{l}\text { Proteomic analysis was performed to identify the special role of } \\
\text { monothiol glutaredoxin } 3 \text { in iron homeostasis regulation. }\end{array}$ \\
\hline & C. neoformans & $\begin{array}{l}\text { Studies have used proteomics to examine pathway responses to } \\
\text { copper stress and high-temperature stress. }\end{array}$ \\
\hline \multirow[t]{2}{*}{$\begin{array}{l}\text { Proteomic Profiles of } \\
\text { Virulence Gene-Edited } \\
\text { Fungal Strains }\end{array}$} & C. albicans & $\begin{array}{l}\text { Proteomic analysis was used to identify protein components of } \\
\text { plasma, and specific functions of regulator involved in cell wall } \\
\text { formation, morphogenesis, cell differentiation, and pathogenicity. }\end{array}$ \\
\hline & C. neoformans & $\begin{array}{l}\text { Proteomic profiles were performed to analyze biofilm, capsule } \\
\text { formation and cell growth. }\end{array}$ \\
\hline \multirow{4}{*}{$\begin{array}{l}\text { Posttranslational } \\
\text { Modifications in } \\
\text { Fungal Pathogenesis }\end{array}$} & C. neoformans & $\begin{array}{l}\text { Kinases involved in the cell cycle, metabolic processes, and } \\
\text { virulence adjustment were detected in phosphoproteomic analysis. }\end{array}$ \\
\hline & A. fumigatus & $\begin{array}{l}\text { Phosphorylation modified proteins were detected under Congo red } \\
\text { and sorbitol induce and caspofungin treatment. }\end{array}$ \\
\hline & $\begin{array}{l}\text { C. neoformans, } \\
\text { C. albicans }\end{array}$ & $\begin{array}{l}\text { Large abundant of ubiquitin proteasome pathway (UPP)-related } \\
\text { proteins were identified by proteomic studies. }\end{array}$ \\
\hline & $\begin{array}{l}\text { C. neoformans, } \\
\text { C. albicans, and } \\
\text { A. fumigatus }\end{array}$ & $\begin{array}{l}\text { Function of histone deacetylases were analyzed by proteomic } \\
\text { studies and acetylomes of baker's yeast and three human fungal } \\
\text { pathogens were compared. }\end{array}$ \\
\hline \multirow[t]{3}{*}{$\begin{array}{l}\text { Secretomic Profiles of } \\
\text { Fungal Pathogens }\end{array}$} & C. neoformans & $\begin{array}{l}\text { Main component proteins of extracellular vesicles and extracellular } \\
\text { proteome were analyzed by MS. }\end{array}$ \\
\hline & C. albicans & $\begin{array}{l}\text { Protein composition of EVs is associated with pathogenesis, cell } \\
\text { organization, carbohydrate and lipid metabolism, branching and } \\
\text { biofilm formation. }\end{array}$ \\
\hline & A. fumigatus & $\begin{array}{l}\text { Proteomic analysis was performed to determine the expression of } \\
\text { secreted proteases in ptrt } \Delta, x p r g \Delta \text {, and ptrt/xprg } \Delta .\end{array}$ \\
\hline \multirow{4}{*}{$\begin{array}{l}\text { Drug Action and } \\
\text { Pharmacological } \\
\text { Effects on Proteomic } \\
\text { Profiles }\end{array}$} & C. gattii & $\begin{array}{l}\text { In a time-course proteomic analysis was performed during } \\
\text { fluconazole treatment. }\end{array}$ \\
\hline & C. albicans & $\begin{array}{l}\text { Proteomic analysis revealed a synergistic mechanism of fluconazole } \\
\text { and berberine against fluconazole-resistance. }\end{array}$ \\
\hline & A. fumigatus & Proteomic analysis was performed in cells treated with itraconazole. \\
\hline & C. glabrata & $\begin{array}{l}\text { Proteomic analysis was performed in fluconazole-induced resistant } \\
\text { strains. }\end{array}$ \\
\hline \multirow{3}{*}{$\begin{array}{l}\text { Vaccine Screening for } \\
\text { Fungal Pathogens }\end{array}$} & C. neoformans, & Secreted and cell wall-bound proteins were identified by \\
\hline & $\begin{array}{l}\text { A. fumigatus, } \\
\text { C. gattii }\end{array}$ & Immunoblot-MS analyses. \\
\hline & $\begin{array}{l}13 \text { fungal } \\
\text { species }\end{array}$ & $\begin{array}{l}\text { Highly conserved secreted and surface proteins from were } \\
\text { identified. }\end{array}$ \\
\hline
\end{tabular}

(Vodisch et al., 2011; Barker et al., 2012; Ding et al., 2014a; Sun et al., 2014; Moloney et al., 2016; Manfiolli et al., 2017; Li et al., 2019a; Silva et al., 2020) (Alkafeef et al., 2020)

(Martinez Barrera et al., 2020; Sun et al., 2021)

(Cabezon et al., 2009; Lee et al., 2010; Santi et al., 2014)

(Olson et al., 2007; Santi et al., 2014; Geddes et al., 2016; Bruni et al., 2017)

(Selvan et al., 2014)

(Mattos et al., 2020a; Mattos et al., 2020b)

(Atir-Lande et al., 2005; Liu and Xue, 2014; Geddes et al., 2016)

(Arras et al., 2017; Li Y. et al., 2019)

(Rodrigues et al., 2008; Vu et al., 2014; Wolf et al., 2014; Vargas et al., 2015; Bielska and May, 2019) (Thomas et al., 2009; Vargas et al., 2015; Wolf et al., 2015)

(Shemesh et al., 2017)

(Chong et al., 2012)

(Xu et al., 2009)

(Gautam et al., 2016)

(Samaranayake et al., 2013)

(Eigenheer et al., 2007; Young et al., 2009; Kumar et al., 2011; Chaturvedi et al., 2013; Martins et al., 2013; Virginio et al., 2014)

(Champer et al., 2016) 
3 (Alkafeef et al., 2020). Similarly, proteomics was used to study the role of copper homeostasis in C. neoformans (Sun et al., 2021). Under copper stress, the proteasome pathway was upregulated and the ribosomal pathway down-regulated. In addition, the ubiquitination level of whole proteins was upregulated under copper stress, and a growth defect could be restored by inhibiting the proteasome pathway (Sun et al., 2021).

Responses of fungal pathogens to high temperatures and osmotic pressures are also key factors affecting infection, but only a few studies have used proteomics to examine those responses. Potential binding partners of septin Cdc10 in $C$. neoformans were scanned using Immunoprecipitation(IP)proteome analysis in order to explain the outstanding protective effect of $\mathrm{Cdc10}$ against high-temperature stress (Martinez Barrera et al., 2020). In A. fumigatus, Sln1p, Msb2p, and Opy2p, upstream sensors of the high-osmolarity glycerol (HOG) pathway, affect osmotic stress response, carbohydrate metabolism, and protein degradation (Silva et al., 2020). Additional proteomic analyses investigating fungal pathogen response to stress should be performed in the future to develop new clinical treatments for fungal disease.

\section{PROTEOMIC PROFILES OF VIRULENCE GENE-EDITED FUNGAL STRAINS}

Virulence factors such as capsules, melanin, morphology, biofilm formation, virulence genes, plasma membranes, and cell wall maintenance have critical roles in fungal pathogen invasion (Crabtree et al., 2012; Dambuza et al., 2018; Mukaremera et al., 2018). Proteomics is a reliable approach to explore regulatory functions of virulence factors (Table 1). For example, in the yeast-to-hyphal transition factor CaKEM1 mutant strain of $C$. albicans, proteomic analysis was used to identify hyphae-specific genes that were regulated (Lee et al., 2010). Proteomic profiles were compared between biofilm cells and planktonic cells of $C$. neoformans in order to better understand the biofilm lifestyle, and proteins involved in oxidation-reduction, proteolysis, transport, translation, and energy acquisition mode were enriched (Santi et al., 2014). In an analysis of protein components of plasma membranes in C. albicans, 12 glycosylphosphatidylinositol(GPI)-anchored membrane proteins were associated with cell wall maintenance and virulence (Cabezon et al., 2009).

Proteomics can also help detect plasma membrane and cellwall regulate genes associated with mutant-specific protein expression. The protein O-mannosyltransferase (Pmt protein) is associated with the cell wall and morphogenesis. Knockout of PMT4 in C. neoformans decreases expression of wall component proteins and leads to protein mannosylation inefficiency (Figure 1B) (Olson et al., 2007). Proteomic analysis also determined that $P K A$ regulates capsule formation through a ubiquitin-proteasome pathway in C. neoformans (Geddes et al., 2016) (Figure 1B). Secretomic analysis of a PKA1 expression-suppression strain revealed five biomarkers of infection, including definitive virulence factors Cig1 and Aph1
(Figure 1B) (Geddes et al., 2015). On the basis of proteomics, the F-box protein Fbp1 affects $C$. neoformans survival in macrophages by regulating inositol sphingolipid biosynthesis (Liu and Xue, 2014). The functions of Gib2 are vital in cell growth, differentiation, and pathogenicity. A two-dimensional echocardiography(2DE)-MS analysis of gib2 $\Delta$ showed that Gib2 was linked to ribosomal biogenesis, protein translation, and stress responses in C. neoformans (Bruni et al., 2017). Virulence factors are potential targets for new antifungal drugs, and thus, further investigations of virulence genes associated with cell walls, plasma membranes, and the cell cycle are needed.

\section{POSTTRANSLATIONAL MODIFICATIONS IN FUNGAL PATHOGENESIS}

In evaluating the virulence of fungal pathogens, epigenetic modifications are a more direct and rapid response to stress. Epigenetic modifications that have received wide attention include PTMs, such as phosphorylation, ubiquitination, and acetylation (Table 1) (Aggarwal et al., 2021; Zhang Y. et al., 2021). Phosphorylation regulates kinase pathways during fungal infection. For example, Hog1 is a ubiquitous MAPK enzyme in fungi that responds to external stimuli such as temperature, osmotic pressure, and oxidative damage. Hog1 is phosphorylated in C. neoformans serotype D but is dephosphorylated in serotype A under stress (Bahn et al., 2006). Forty-five kinases involved in the cell cycle, metabolic processes, and virulence adjustment were detected in phosphoproteomic analysis in C. neoformans, and the kinases included protein kinase C, Bck1, Mkk2, and Mpl1 (Selvan et al., 2014). Similar studies have been conducted on A. fumigatus. Knockout of Hog1 homologous genes SAKA and $M P K C$ in $A$. fumigatus increased sensitivity to osmotic and oxidative stress and cell damages. Congo red and sorbitol induce MpkC phosphorylation modification in A. fumigatus (Figure 1C) (Bruder Nascimento et al., 2016). Phosphorylation modification was also detected on p38 (CMGC/MAPK/p38/ Hog) (Mattos et al., 2020b). Low expression of phosphorylase in $\operatorname{sak} A \Delta, m p k C \Delta$, and $m p k C / s a k A \Delta \Delta$ indicates that phosphorylation is essential for MpkA to maintain cell walls (Figure 1C) (Mattos et al., 2020b). Meanwhile, with caspofungin treatment, phosphorylated proteins included transcription factors, protein kinases, and cytoskeletal proteins. In sakA $\Delta$, $m p k A \Delta$, and $m p k A / s a k A \Delta \Delta$, phosphorylation levels of metabolic and transcriptional regulatory proteins, DNA/RNA binding proteins, and cell cycle control proteins are down-regulated (Figure 1C). When treated with caspofungin, phosphorylation levels of protein kinases A (PKA) regulatory subunit, protein kinases $\mathrm{C}$ (PKC phosphorus transcription factor AtfA/AtfB/ AtfD), and transcription factor ZipD were down-regulated (Mattos et al., 2020a). Therefore, regulation of the MAPK pathway by affecting posttranslational modifications is a potential target for new drugs.

As described above, stress response pathways in fungi facilitate survival and adaptation during infection. Geddes et al. (2016) used proteomics to identify the effect of PKA1 mutation 
on intracellular proteins in C. neoformans and 302 differentially expressed proteins were identified. Ribosome and translationrelated proteins were the most abundant in protein-protein interactions, whereas ubiquitin proteasome pathway (UPP)related proteins were the second most abundant (Geddes et al., 2016). UPP damage is associated with pathogenesis of a variety of neurodegenerative diseases, including Alzheimer's, Parkinson's, and Huntington's, suggesting that UPP plays a critical role in maintaining cellular protein homeostasis (Huang and Figueiredo-Pereira, 2010; Nijholt et al., 2011). The SCF (Skp1, Cullins, and F-box proteins) E3 ubiquitin ligases are involved in various biological processes in pathogenic fungi. In C. neoformans, Liu et al. (2011) demonstrated that $\mathrm{SCF}^{\mathrm{Fbp} 1} \mathrm{E} 3$ ubiquitin ligase is indispensable during infection. In an FBP1 knockout strain, fungal pulmonary burden and proliferation ability in macrophages decrease, resulting in inability to migrate in a host (Liu and Xue, 2014). Fbp1 also helps mediate sexual reproduction in C. neoformans (Liu et al., 2011). In C. albicans, SCF E3 ubiquitin ligase helps regulates mycelial morphology (Butler et al., 2006). For example, SCF ${ }^{\mathrm{Cdc} 4}$ is involved in negative regulation of fungal filaments (Atir-Lande et al., 2005), whereas SCF ${ }^{\mathrm{Grr}}$ is involved in negative regulation of pseudomycelia (Butler et al., 2006). In Aspergillus nidulans, $\mathrm{SCF}^{\mathrm{Grr}}$ is involved in meiosis and sexual sporogenesis (Krappmann et al., 2006). These results indicate that the ubiquitin-proteasome pathway is involved in cell cycle regulation and fungal transformation.

Autophagy also helps to maintain protein homeostasis in cells. Autophagy is a response to various environmental stresses, such as nutritional deficiencies and hypoxia (Shliapina et al., 2021). Many studies show that induction of autophagy depends primarily on the serine/threonine protein kinase TOR regulating the phosphorylation level of the core Atg protein (Jung et al., 2010; Paquette et al., 2018; Wang and Zhang, 2019). In yeast, TOR regulates the phosphorylation level of Atg13, resulting in a decrease in the affinity between Atg1 and its binding proteins, and subsequently inhibits the initiation of autophagy under nutrient-rich conditions (Kawamata et al., 2008; Jung et al., 2010). In addition, several Atg proteins undergo changes in acetylation state, indicating that acetylation modification is very important in the regulation of autophagy (Lee and Finkel, 2009; Yi et al., 2012; Banreti et al., 2013). Acetylation is also involved in many other biological processes and cellular activities of fungi, including host adaptability, genome stability, production of virulence factors, synthesis of secondary metabolites, and fungal drug resistance (Lee et al., 2009; Wurtele et al., 2010; Lu et al., 2012; Lamoth et al., 2014; Brandao et al., 2015; Freire-Beneitez et al., 2016). In C. neoformans, deletion of the histone deacetylases SIR2, HST3, and HST4 significantly altered the epigenetic landscape and virulence (Arras et al., 2017). Essential in the pathogenesis in C. neoformans is the deacetylases Sir2, Hst3, Hst4, Dac2, Dac6, Dac4, Dac5, and Dac11 (Figure 1B) (Li Y. et al., 2019). Li Y. et al. (2019) also compared acetylomes of baker's yeast and three human fungal pathogens (C. neoformans, C. albicans, and A. fumigatus). Thus, the acetylation motifs of fungal pathogens participate in mediating pathogenicity and therefore are subject to selective evolution (Li Y. et al., 2019). The study provides a reference for further investigations of the evolution of protein translational modifications in pathogenic fungi.

\section{SECRETOMIC PROFILES OF FUNGAL PATHOGENS}

Extracellular vesicles (EVs) deliver secretory proteins into a host. In C. neoformans, 76 proteins in EVs are linked to virulence and protection against oxidative stress during infection (Rodrigues et al., 2008). With increased technological sensitivity, another 147 proteins were identified as main component proteins in EVs (Wolf et al., 2014). Composition of EV proteins is closely associated with virulent phenotypes (Vargas et al., 2015; Bielska and May, 2019). C. neoformans needs to penetrate the blood brain barrier (BBB) in order to invade the central nervous system, and vesicles play an important role in that process $(\mathrm{Vu}$ et al., 2014). A secreted metalloproteinase, Mpr1, identified in extracellular proteome analysis was found to play an important role in breaching the BBB (Vu et al., 2014). In C. albicans, protein composition of EVs is associated with pathogenesis, cell organization, carbohydrate and lipid metabolism, and response to stress (Vargas et al., 2015). For example, a VPS4 mutation in C. albicans leads to reductions in normally secreted proteins, which may associated with altered branching and biofilm formation (Thomas et al., 2009). Defects in lipid biosynthetic genes CHO1, $P S D 1$, and PSD2 lead to significant changes in the exponential cargo of EVs (Wolf et al., 2015). Mutation in the cell wall protein-encoding gene DSE1 leads to a lack of chitin biosynthesis protein Chs5 and stimulates the expression of the cell wall degrading-related protein glucoamylase 1 (Zohbi et al., 2014). In A. fumigatus, the release of extracellular proteases to degrade host structures is also an important fungal virulence factor. Transcription factors $\mathrm{XprG}$ and PrtT regulate extracellular proteolysis. Proteomic analysis was performed to determine the expression of secreted proteases in ptrt $\Delta$, xprg $\Delta$, and $p t r t / x p r g \Delta$, and the expression levels of 24 proteases, 18 glucanases, 6 chitinases, and 19 allergens decreased by two to fivefold (Shemesh et al., 2017). Because secretory proteins affect fungal virulence from several aspects, secretomes of pathogenic fungi are currently a hot topic of research.

\section{DRUG ACTION AND PHARMACOLOGICAL EFFECTS ON PROTEOMIC PROFILES}

Fluconazole, voriconazole, and itraconazole are widely used in prophylactic and maintenance therapies (Day et al., 2013; Rajasingham et al., 2017). In a time-course proteomic analysis of Cryptococcus gattii during fluconazole treatment, most ribosomal proteins decreased, whereas mitochondrial respiratory chain, plasma membrane, and heat shock proteins and those associated with sugar metabolism and ATP synthesis 
increased (Figure 1D) (Chong et al., 2012). In C. albicans, proteomic analysis revealed a synergistic mechanism of fluconazole and berberine against fluconazole-resistance. Mitochondrial membrane potential, endogenous reactive oxygen species (ROS) production, and the TCA cycle (Aco1, Idp2) were up-regulated; whereas ATP content, ATP-synthase (complex V) activity, and glycolysis (Fba1, Eno1) were down-regulated (Figure 1D) (Xu et al., 2009). In A. fumigatus cells treated with itraconazole, abundances of $14 \alpha$-sterol demethylases, transmembrane proteins, G-protein complexes, glucan modifying enzymes, glucanosyl transferases, and glucan synthases were altered (Figure 1D) (Gautam et al., 2016). Eight fluconazole-induced resistant strains of Candida glabrata changed in expression of proteins associated with bud formation and metallothionein production (Samaranayake et al., 2013).

Some natural compounds are effective antifungal agents, and proteomic analysis has been used to explore their affected targets and mechanisms of control. Myristic acid (MA) and oleic acid affect biofilm formation and virulence of $C$. albicans by regulating ergosterol synthesis, sphingolipid metabolism, and lipase production proteins (Figure 1E) (Prasath et al., 2019; Muthamil et al., 2020). In A. fumigatus exposed to cis-9hexadecenal, PKS enzymes are up-regulated and the 1,8dihydroxynaphthalene-melanin biosynthesis pathway is downregulated. Induced oxidative stress is also an important mechanism of candidate antifungal agents. N-chlorotaurine inhibits conidial and mycelial growth in A. fumigatus by upregulating the oxidative stress response (Sheehan et al., 2019). Atorvastatin has treatment potential because it induces oxidative stress and alters membrane permeability in A. fumigatus (Ajdidi et al., 2020). Such novel antifungal drugs are welcomed additions in clinical therapy.

\section{VACCINE SCREENING FOR FUNGAL PATHOGENS}

Extracellular proteins participate in fungal pathogenesis as immunoreactive antigens (Zhang L. et al., 2021). In an analysis of secreted and cell wall-bound proteins in C. neoformans, extracellular proteins possessed immunogenicity and proteolytic ability for the glycosylphosphatidylinositolanchored proteins that were recruited to the cell wall (Eigenheer et al., 2007). Immunoblot-MS analyses have been conducted with fungal pathogens to identify diagnostic markers or candidate antigens for development of vaccines and immunotherapy (Young et al., 2009; Kumar et al., 2011; Chaturvedi et al., 2013; Martins et al., 2013; Virginio et al., 2014). Highly conserved secreted and surface proteins from 13 fungal species were identified, including the following 1,3- $\beta$ glucanosyltransferases: Gel1, Gel2, Gel3, Gel4, Bgt1, Crf1, Ecm33, EglC, Sed2, Asp f15, ALP2, and carboxypeptidase S1. Gell and Crf1 were screened as promising vaccine candidates (Figure 1F) (Champer et al., 2016). Vaccines are widely used to prevent bacterial and viral infections; however, some obstacles impede vaccine development for fungal pathogens. For example, $\beta$-1,3-D-glucan, a key component of fungal cell walls, is poorly immunogenic (Armstrong-James et al., 2017). The sensitivity and high throughput of mass spectrometry have been improved, creating unprecedented opportunities to exploit fungal vaccine. However, the fungal vaccines are still on the way.

\section{PROTEOMES AND PTMS IN PHAGOCYTOSIS DURING FUNGI INVASION}

Fungal pathogens and their hosts require rapid modulation of virulence and defense mechanisms. Fungal pathogens have developed rapid and precise gene expression, protein translation, and PTM regulation mechanisms in order to colonize, invade, and replicate during systemic infection, summarized in Table 2 (Butler et al., 2009; Kronstad et al., 2011; Kronstad et al., 2012; Li H. L. et al., 2019; Bruno et al., 2020). In pathogens, virulence factors also evolved to resist host obstruction and interception, including capsules, melanin, biofilms, and growth at $37^{\circ} \mathrm{C}$, among others (Cherniak and Sundstrom, 1994; Crabtree et al., 2012; Dambuza et al., 2018; Suo et al., 2018; Casadevall et al., 2019). To counter pathogenic invasion, host cells trigger a series of response cascades, restrict essential nutrients, produce cytokines and chemokines, induce infiltration of immune cells, and consequently activate eliminating mechanisms (Campuzano and Wormley, 2018; Casadevall et al., 2018).

Immunohistochemical staining, quantitative polymerase chain reaction, western blot, transcriptome analysis, and proteome and PTM analyses have provided valuable information on interactions between hosts and invading fungi. Phagocytosis by macrophages and glucose metabolism play important roles in interactions between pathogens and hosts (Rohatgi and Pirofski, 2015; Hansakon et al., 2019). The infection process is a complex of interactions between pathogen and host at RNA, protein, PTM, and metabolic levels. When a host was invaded, phagocytosis by macrophages clears invading pathogens (Li H. L. et al., 2019; Sun et al., 2019; Nelson et al., 2020; Seoane et al., 2020). Many studies show that phagosomes have a fundamental and distinct role in fungal infections (Sorrell et al., 2016; Santiago-Tirado and Doering, 2017; Santiago-Tirado et al., 2017; Li H. L. et al., 2019; Giusiano, 2020; Scherer et al., 2020), with phagocytosis regulated by both protein and PTM levels. Reales-Calderón characterized the proteomic differences between human M1 and M2 polarized macrophages in both basal conditions and in response to $C$. albicans. They identified metabolic routes and cytoskeletal rearrangement components as the most relevant differences between $\mathrm{M} 1$ and $\mathrm{M} 2$. In addition, the switch from M1 to M2 may contribute to C. albicans pathogenicity by decreasing generation of specific immune responses or as part of a host attempt to reduce inflammation 
TABLE 2 | Summary of proteomic studies in host-fungal interaction.

\begin{tabular}{|c|c|c|c|c|}
\hline Functions & $\begin{array}{l}\text { Proteomics or } \\
\text { PTMs }\end{array}$ & Pathogen and host & Description & Reference \\
\hline \multirow[t]{7}{*}{ Phagocytosis } & proteomics & $\begin{array}{l}\text { C. albicans, Human blood derived } \\
\text { macrophages(M1 and } \mathrm{M} 2 \\
\text { macrophage) }\end{array}$ & $\begin{array}{l}\text { Characterized the proteomic differences between human M1 and M2 polarized } \\
\text { macrophages in response to } C \text {. albicans. }\end{array}$ & $\begin{array}{l}\text { (Reales- } \\
\text { Calderon } \\
\text { et al., 2014). }\end{array}$ \\
\hline & $\begin{array}{l}\text { proteomics, } \\
\text { phosphorylation }\end{array}$ & C. albicans, RAW 264.7 & $\begin{array}{l}\text { Quantify macrophage proteins and phosphoproteins in RAW } 264.7 \text { exposed to } \\
\text { C. albicans. }\end{array}$ & $\begin{array}{l}\text { (Reales- } \\
\text { Calderon } \\
\text { et al., 2013). }\end{array}$ \\
\hline & $\begin{array}{l}\text { proteomics, } \\
\text { phosphorylation }\end{array}$ & C. albicans, THP-1 macrophage & $\begin{array}{l}\text { Quantitative proteomic and phosphoproteomic of human macrophage ATP- } \\
\text { binding proteins exposed to C. albicans. }\end{array}$ & $\begin{array}{l}\text { (Vaz et al., } \\
\text { 2019) }\end{array}$ \\
\hline & phosphorylation & C. neoformans, RAW264.7 & $\begin{array}{l}\text { Phosphoproteomic analysis of host response to C. neoformans infection in } \\
\text { murine macrophage. }\end{array}$ & $\begin{array}{l}\text { (Pandey } \\
\text { et al., 2017) }\end{array}$ \\
\hline & $\begin{array}{l}\text { proteomics, } \\
\text { lipidomics, and } \\
\text { metabolomics }\end{array}$ & $\begin{array}{l}\text { C. neoformans, murine bone marrow- } \\
\text { derived macrophages and } \\
\text { macrophages derived from human } \\
\text { monocytes }\end{array}$ & $\begin{array}{l}\text { Combination of proteomics, lipidomics, and metabolomics to investigate the } \\
\text { roles of EVs from infected murine bone marrow-derived macrophages and } \\
\text { macrophages derived from human monocytes interaction with Cryptococcus. }\end{array}$ & $\begin{array}{l}\text { (Zhang L. } \\
\text { et al., 2021) }\end{array}$ \\
\hline & proteomics & C. neoformans, mouse & $\begin{array}{l}\text { Comparison of transcriptome and proteome in lung tissues of } C \text {. neoformans- } \\
\text { infected mice. }\end{array}$ & $\begin{array}{l}\text { (Li et al., } \\
2020)\end{array}$ \\
\hline & proteomics & A. fumigatus, RAW 264.7 & $\begin{array}{l}\text { Comparative proteomic analysis of mouse macrophage phagolysosomes } \\
\text { containing melanized wild-type or nonmelanized pksP mutant conidia. }\end{array}$ & $\begin{array}{l}\text { (Schmidt } \\
\text { et al., 2018) }\end{array}$ \\
\hline \multirow[t]{5}{*}{$\begin{array}{l}\text { Energy } \\
\text { Metabolism }\end{array}$} & proteomics & C. albicans and serum & Time-course proteomics in C. albicans in the presence or absence of FBS. & $\begin{array}{l}\text { (Aoki et al., } \\
\text { 2013a; Aoki } \\
\text { et al., 2013b) }\end{array}$ \\
\hline & $\begin{array}{l}\text { proteomics, } \\
\text { phosphorylation }\end{array}$ & C. albicans, THP-1 macrophage & $\begin{array}{l}\text { Quantitative proteomic and phosphoproteomic of human macrophage ATP- } \\
\text { binding proteins exposed to C. albicans. }\end{array}$ & $\begin{array}{l}\text { (Vaz et al., } \\
\text { 2019) }\end{array}$ \\
\hline & proteomics & A. fumigatus, A549 & Characterized the proteomic response of $\mathrm{A} 549$ exposed to $A$. fumigatus & $\begin{array}{l}\text { (Margalit } \\
\text { et al., 2020) }\end{array}$ \\
\hline & proteomics & C. gattii, rat & $\begin{array}{l}\text { Identify differentially expressed proteins induced by a } C \text {. gattii in a rat model by } \\
\text { a shotgun proteomics }\end{array}$ & $\begin{array}{l}\text { (Rosa et al., } \\
\text { 2019) }\end{array}$ \\
\hline & acetylation & C. neoformans, mouse & $\begin{array}{l}\text { Comparative acetylome analysis in mouse model during C. neoformans } \\
\text { infections }\end{array}$ & $\begin{array}{l}\text { (Li et al., } \\
\text { 2020) }\end{array}$ \\
\hline
\end{tabular}

and limit damage from infection, which would increase fungal survival and colonization (Reales-Calderon et al., 2014). RealesCalderon et al. (2013) used MS to quantify macrophage proteins and phosphoproteins in murine macrophages cell line RAW 264.7 exposed to C. albicans. They identified 68 differentially expressed macrophage proteins and 196 differentially abundant phosphorylation peptides, which altered pathways associated with receptors, mitochondrial ribosomal proteins, cytoskeletal proteins, and transcription factor activators involved in inflammatory and oxidative responses and apoptosis. The results suggested that apoptosis is a central pathway in the immune defense against C. albicans invasion (Reales-Calderon et al., 2013). Recently, Vaz et al. (2019) used a quantitative proteomic and phosphoproteomic approach to study human macrophage ATP-binding proteins exposed to C. albicans. They identified 59 differentially abundant ATP binding proteins, including 6 kinases (MAP2K2, SYK, STK3, MAP3K2, NDKA, and SRPK1), consistent with previous studies (Figure 1G) (Hole and Wormley, 2016; Ballou and Johnston, 2017; Vaz et al., 2019). Similar to C. albicans, in the initiation of C. neoformans infections, macrophages are the main phagocytic cells, and M1 macrophages can effectively inhibit pathogen spread. Nevertheless, C. neoformans can survive and reproduce inside macrophages. Consequently, macrophages can be a niche for pathogens to survive and spread. Pandey et al. (2017) found that host autophagy initiation complex (AIC), which regulates fungal colonization of mice, was regulated through kinase activities of upstream regulatory components of AIC, LKB1 and AMPK $\alpha 1$. Their discovery was based on a global phosphoproteomic analysis of host response to C. neoformans infection in murine macrophage cells (RAW264.7) using semi-quantitative, labelfree nano liquid chromatography-MS/MS. They identified 1,268 differentially phosphorylated host proteins deemed responsive to C. neoformans (1.5 fold-change), which indicated a reprograming of host kinase pathways, especially in the AIC. Knockout of AMPK $\alpha 1$ in monocytes of mice results in resistance to fungal colonization (Figure 1H) (Pandey et al., 2017). To further understand the interaction between C. neoformans and macrophages, Zhang L. et al. (2021) used a combination of proteomics, lipidomics, and metabolomics to investigate the roles of EVs from infected murine bone marrow-derived macrophages and macrophages derived from human monocytes in the interaction with Cryptococcus. Pathwayassociated p53, cell cycle and division, extracellular matrix receptors, and phosphatidylcholine were significantly enriched (Zhang L. et al., 2021). Consistent with in vitro investigations above, Li et al. (2020) compared the transcriptome and proteome in lung tissues of C. neoformans-infected C57BL/6J mice. They found a distinct set of differentially expressed genes and similar gene ontology (GO) and Kyoto Encyclopedia of Genes and Genomes (KEGG) enrichment analyses, which may be the result of different levels of PTMs (Li et al., 2020). Host 
phagosomes and energy metabolism are regulated at the pathogen-host axis at proteome and PTM levels and may play important roles during antagonistic interactions (Pandey et al., 2017; Schmidt et al., 2018; Li H. L. et al., 2019; Rosa et al., 2019; Sim et al., 2019; Sun et al., 2019; Vaz et al., 2019; Li et al., 2020; Nelson et al., 2020; Seoane et al., 2020). With the human fungal pathogen A. fumigatus, Schmidt et al. (2018) conducted a comparative proteomic analysis of mouse macrophage phagolysosomes containing melanized wild-type or nonmelanized $p k s P$ mutant conidia (Schmidt et al., 2018). Bioinformatical analysis of differentially expressed proteins revealed enriched pathways included vATPase-driven phagolysosomal acidification, Rab5 and Vamp8-dependent endocytic trafficking, and recruitment of Lamp1 phagolysosomal maturation marker and lysosomal cysteine protease cathepsin $\mathrm{Z}$. Particularly notable, the proteome of invading A. fumigatus contained 22 differentially expressed proteins. Most importantly, the distinct roles of macrophages during fungal infections in humans remain to be confirmed.

\section{HOST ENERGY METABOLISM IN HOST-FUNGI INTERACTIONS}

Energy metabolism, especially glucose and fatty acid metabolism, plays critical roles at the pathogen-host axis at both RNA and protein levels (Table 2) (Li H. L. et al., 2019; Li et al., 2020). Glucose is a primary factor in the competition between host and invading pathogen, and its metabolism is critical for fungal survival (Idnurm et al., 2007; Li H. L. et al., 2019). In fungal pathogens, adaption to a nutritionally deficient environment is also a key factor in pathogenicity. In C. albicans, carbon sources influence biofilm formation and drug resistance by regulating cell wall components and those of the secretome, including adherence and pheromone-regulated proteins (Ene et al., 2012). According to time-course proteomics in yeast nitrogen base \pm Fetal Bovine Serum (FBS) media, pathways associated with transport, detoxification, energy metabolism, and iron acquisition were enriched in C. albicans (Aoki et al., 2013a; Aoki et al., 2013b). Furthermore, Li H. L. et al. (2019) found that compared with in vitro $C$. neoformans results, in vivo glycolysis and TCA cycle pathways varied in C. neoformans isolated from both mouse and monkey infection models (Li H. L. et al., 2019). From the host aspect, as mentioned before, Vaz et al. (2019) used a quantitative proteomic and phosphoproteomic approach to study human macrophage ATP-binding proteins during $C$. albicans infections. They found significantly altered ATP and macrophage mitochondrial proteins, indicating energy metabolism of phagocytosis was also altered during C. albicans infections. Margalit et al. (2020) characterized the proteomic response of A549 exposed to A. fumigatus and identified changes in mitochondrial activity and energy output (Margalit et al., 2020). Rosa et al. (2019) used a shotgun proteomics approach to identify differentially expressed proteins induced by a C. gattii clinical strain in a rat model and found a potential Warburg-like effect (Rosa et al., 2019). Briefly, rat lungs were isolated for three days post incubation with avirulent and virulent C. gatti strains and then analyzed by MS/MS. Infection by C. gattii induced a dramatic change in protein expression, especially that of proteins related to energy metabolism, such as those involved in the aerobic glycolysis cycle, TCA cycle, and pyrimidine and purine metabolism. These results indicated C. gattii infection triggers important changes in energy metabolism that lead to activation of glycolysis and lactate accumulation, culminating in a cancerlike metabolic status known as the Warburg effect. Li et al. (2020) found similar results in mouse lung tissues at day seven postinfection with C. neoformans. They performed acetylome analysis and found that the reactome of differentially expressed Kac proteins primarily included those involved in glucose and fatty acid metabolism (Li et al., 2020). Because of the important roles of energy during infection progression, glucose metabolism and mitochondrial function have gradually become the focus of research in infectious diseases, from both host and pathogen aspects. Deciphering the mechanisms of co-evolution at fungihost axis, which deserves more attention, will contribute the therapy for fungal diseases and development of novel antifungal drugs.

\section{QUESTIONS AND OUTLOOK}

This literature review summarizes the many applications of MSbased proteome and PTM analyses that have increased understanding of fungal pathogenesis and interactions between pathogens and hosts. With increases in MS throughput and precision, proteomics is now widely used in the life sciences. Much has been learned using standard fungal strains, including C. albicans, A. fumigatus, C. neoformans, and C. auris, and samples from infected animal models, including mice and rats and cell lines such as RAW264.7, A549, and THP-1. However, shortcomings remain in this area. First, human-relevant samples are limited to only those with monocytes or body fluids. Second, differences among clinical fungal strains or primary cell types and in specific organs/tissues are far too great to ignore. Third, interactions of proteomes and regulation mechanisms among PTMs are poorly understood. In addition, although proteomics together with other omics can serve as comprehensive displays of cellular transcriptional levels, unfortunately, most multiomic studies are presented without simultaneous analyses and functional experiments (Zamith-Miranda et al., 2019; Zhou et al., 2021). This lack of supporting studies may be due to constraints with database integration and interconnectivity of omics data (Song M. et al., 2020). Over the past decade, a series of multiomics tools and data sets have proven to be valuable. However, simultaneously, higher requirements have become necessary for data operation, and computational resources, ethical regulatory issues associated with data sharing, application of machine and deep learning, and development of data visualization tools need to be addressed (Krassowski et al., 2020). With the advent of the big data era, combined multiomics 
is expected to be a very powerful tool in future research on pathogenic fungi. Furthermore, there is a great potential to improve MS techniques, particularly to increase detection resolution. In addition, dual-proteome or dual-PTM analyses of pathogens and host are difficult to conduct and need to be improved. In the future, mass spectrometry will be used to identify important proteins, PTMs, and their functions in the fungi and fungi-host interaction repertoire, and benefits for fungal therapeutics and vaccine development. Overall, MS is a novel approach that will continue to help decipher mechanisms of fungal diseases. Understanding fungal pathogenesis and clinically relevant interactions between host and fungal strains contributes to the development of novel clinical therapies and antifungal drugs and helps to identify clinical biomarkers to combat deadly fungal infections and decrease morbidity and mortality.

\section{REFERENCES}

Aggarwal, S., Tolani, P., Gupta, S., and Yadav, A. K. (2021). Posttranslational Modifications in Systems Biology. Adv. Protein Chem. Struct. Biol. 127, 93-126. doi: 10.1016/bs.apcsb.2021.03.005

Ajdidi, A., Sheehan, G., and Kavanagh, K. (2020). Exposure of Aspergillus Fumigatus to Atorvastatin Leads to Altered Membrane Permeability and Induction of an Oxidative Stress Response. J. Fungi (Basel) 6 (2), 42. doi: 10.3390/jof6020042

Alhumaid, S., Al Mutair, A., Al Alawi, Z., Alshawi, A. M., Alomran, S. A., Almuhanna, M. S., et al. (2021). Coinfections With Bacteria, Fungi, and Respiratory Viruses in Patients With SARS-CoV-2: A Systematic Review and Meta-Analysis. Pathogens 10 (7), 809. doi: 10.3390/pathogens10070809

Alkafeef, S. S., Lane, S., Yu, C., Zhou, T., Solis, N. V., Filler, S. G., et al. (2020). Proteomic Profiling of the Monothiol Glutaredoxin Grx3 Reveals Its Global Role in the Regulation of Iron Dependent Processes. PloS Genet. 16 (6), e1008881. doi: 10.1371/journal.pgen.1008881

Aoki, W., Tatsukami, Y., Kitahara, N., Matsui, K., Morisaka, H., Kuroda, K., et al. (2013a). Elucidation of Potentially Virulent Factors of Candida Albicans During Serum Adaptation by Using Quantitative Time-Course Proteomics. J. Proteomics 91, 417-429. doi: 10.1016/j.jprot.2013.07.031

Aoki, W., Ueda, T., Tatsukami, Y., Kitahara, N., Morisaka, H., Kuroda, K., et al. (2013b). Time-Course Proteomic Profile of Candida Albicans During Adaptation to a Fetal Serum. Pathog. Dis. 67 (1), 67-75. doi: 10.1111/2049632X.12003

Armstrong-James, D., Brown, G. D., Netea, M. G., Zelante, T., Gresnigt, M. S., van de Veerdonk, F. L., et al. (2017). Immunotherapeutic Approaches to Treatment of Fungal Diseases. Lancet Infect. Dis. 17 (12), e393-e402. doi: 10.1016/S14733099(17)30442-5

Arras, S. D. M., Chitty, J. L., Wizrah, M. S. I., Erpf, P. E., Schulz, B. L., Tanurdzic, M., et al. (2017). Sirtuins in the Phylum Basidiomycota: A Role in Virulence in Cryptococcus Neoformans. Sci. Rep. 7, 46567. doi: 10.1038/srep46567

Atir-Lande, A., Gildor, T., and Kornitzer, D. (2005). Role for the SCFCDC4 Ubiquitin Ligase in Candida Albicans Morphogenesis. Mol. Biol. Cell 16 (6), 2772-2785. doi: 10.1091/mbc.e05-01-0079

Bahn, Y. S., Kojima, K., Cox, G. M., and Heitman, J. (2006). A Unique Fungal Two-Component System Regulates Stress Responses, Drug Sensitivity, Sexual Development, and Virulence of Cryptococcus Neoformans. Mol. Biol. Cell 17 (7), 3122-3135. doi: 10.1091/mbc.e06-02-0113

Ballou, E. R., and Johnston, S. A. (2017). The Cause and Effect of Cryptococcus Interactions With the Host. Curr. Opin. Microbiol. 40, 88-94. doi: 10.1016/ j.mib.2017.10.012

Banreti, A., Sass, M., and Graba, Y. (2013). The Emerging Role of Acetylation in the Regulation of Autophagy. Autophagy 9 (6), 819-829. doi: 10.4161/ auto. 23908

\section{AUTHOR CONTRIBUTIONS}

Writing-original draft preparation: TS, HL, YL, and CD. Writing-review and editing: CD. All authors contributed to the review and approved the submitted version.

\section{FUNDING}

This review was supported by the National Natural Science Foundation of China (31870140 to CD and 81801989 to TS), the Liaoning Revitalization Talents Program (XLYC1807001 to CD), the Beijing Natural Science Foundation (5184037 to TS), the Fundamental Research Funds for the Central Universities (3332018024 to TS), and the China Postdoctoral Science Foundation (2021M693520 to HL).

Barker, B. M., Kroll, K., Vodisch, M., Mazurie, A., Kniemeyer, O., and Cramer, R. A. (2012). Transcriptomic and Proteomic Analyses of the Aspergillus Fumigatus Hypoxia Response Using an Oxygen-Controlled Fermenter. BMC Genomics 13, 62. doi: 10.1186/1471-2164-13-62

Bielska, E., and May, R. C. (2019). Extracellular Vesicles of Human Pathogenic Fungi. Curr. Opin. Microbiol. 52, 90-99. doi: 10.1016/j.mib.2019.05.007

Brandao, F. A., Derengowski, L. S., Albuquerque, P., Nicola, A. M., Silva-Pereira, I., and Pocas-Fonseca, M. J. (2015). Histone Deacetylases Inhibitors Effects on Cryptococcus Neoformans Major Virulence Phenotypes. Virulence 6 (6), 618 630. doi: 10.1080/21505594.2015.1038014

Bruder Nascimento, A. C., Dos Reis, T. F., de Castro, P. A., Hori, J. I., Bom, V. L., de Assis, L. J., et al. (2016). Mitogen Activated Protein Kinases SakA(HOG1) and MpkC Collaborate for Aspergillus Fumigatus Virulence. Mol. Microbiol. 100 (5), 841-859. doi: 10.1111/mmi.13354

Bruni, G. O., Battle, B., Kelly, B., Zhang, Z., and Wang, P. (2017). Comparative Proteomic Analysis of Gib2 Validating Its Adaptor Function in Cryptococcus Neoformans. PloS One 12 (7), e0180243. doi: 10.1371/journal.pone.0180243

Bruno, M., Kersten, S., Bain, J. M., Jaeger, M., Rosati, D., Kruppa, M. D., et al. (2020). Transcriptional and Functional Insights Into the Host Immune Response Against the Emerging Fungal Pathogen Candida Auris. Nat. Microbiol. 5 (12), 1516-1531. doi: 10.1038/s41564-020-0780-3

Butler, D. K., All, O., Goffena, J., Loveless, T., Wilson, T., and Toenjes, K. A. (2006). The GRR1 Gene of Candida Albicans Is Involved in the Negative Control of Pseudohyphal Morphogenesis. Fungal Genet. Biol. 43 (8), 573-582. doi: 10.1016/j.fgb.2006.03.004

Butler, G., Rasmussen, M. D., Lin, M. F., Santos, M. A., Sakthikumar, S., Munro, C. A., et al. (2009). Evolution of Pathogenicity and Sexual Reproduction in Eight Candida Genomes. Nature 459 (7247), 657-662. doi: 10.1038/nature08064

Cabezon, V., Llama-Palacios, A., Nombela, C., Monteoliva, L., and Gil, C. (2009). Analysis of Candida Albicans Plasma Membrane Proteome. Proteomics 9 (20), 4770-4786. doi: 10.1002/pmic.200800988

Campuzano, A., and Wormley, F. L. (2018). Innate Immunity Against Cryptococcus, From Recognition to Elimination. J. Fungi (Basel) 4 (1), 33. doi: $10.3390 /$ jof 4010033

Casadevall, A., Coelho, C., and Alanio, A. (2018). Mechanisms of Cryptococcus Neoformans-Mediated Host Damage. Front. Immunol. 9:855. doi: 10.3389/ fimmu.2018.00855

Casadevall, A., Coelho, C., Cordero, R. J. B., Dragotakes, Q., Jung, E., Vij, R., et al. (2019). The Capsule of Cryptococcus Neoformans. Virulence 10 (1), 822-831. doi: 10.1080/21505594.2018.1431087

Champer, J., Ito, J. I., Clemons, K. V., Stevens, D. A., and Kalkum, M. (2016). Proteomic Analysis of Pathogenic Fungi Reveals Highly Expressed Conserved Cell Wall Proteins. J. Fungi (Basel) 2 (1), 6. doi: 10.3390/jof2010006

Chaturvedi, A. K., Weintraub, S. T., Lopez-Ribot, J. L., and Wormley, F. L.Jr. (2013). Identification and Characterization of Cryptococcus Neoformans 
Protein Fractions That Induce Protective Immune Responses. Proteomics 13 (23-24), 3429-3441. doi: 10.1002/pmic.201300213

Cherniak, R., and Sundstrom, J. B. (1994). Polysaccharide Antigens of the Capsule of Cryptococcus Neoformans. Infect. Immun. 62 (5), 1507-1512. doi: 10.1128/ iai.62.5.1507-1512.1994

Chong, H. S., Campbell, L., Padula, M. P., Hill, C., Harry, E., Li, S. S., et al. (2012). Time-Course Proteome Analysis Reveals the Dynamic Response of Cryptococcus Gattii Cells to Fluconazole. PloS One 7 (8), e42835. doi: 10.1371/journal.pone.0042835

Crabtree, J. N., Okagaki, L. H., Wiesner, D. L., Strain, A. K., Nielsen, J. N., and Nielsen, K. (2012). Titan Cell Production Enhances the Virulence of Cryptococcus Neoformans. Infect. Immun. 80 (11), 3776-3785. doi: 10.1128/ IAI.00507-12

Dambuza, I. M., Drake, T., Chapuis, A., Zhou, X., Correia, J., Taylor-Smith, L., et al. (2018). The Cryptococcus Neoformans Titan Cell Is an Inducible and Regulated Morphotype Underlying Pathogenesis. PloS Pathog. 14 (5), e1006978. doi: 10.1371/journal.ppat.1006978

Day, J. N., Chau, T. T. H., Wolbers, M., Mai, P. P., Dung, N. T., Mai, N. H., et al. (2013). Combination Antifungal Therapy for Cryptococcal Meningitis. N. Engl. J. Med. 368 (14), 1291-1302. doi: 10.1056/NEJMoa1110404

Ding, C., and Butler, G. (2007). Development of a Gene Knockout System in Candida Parapsilosis Reveals a Conserved Role for BCR1 in Biofilm Formation. Eukaryot Cell 6 (8), 1310-1319. doi: 10.1128/EC.00136-07

Ding, C., Festa, R. A., Chen, Y. L., Espart, A., Palacios, O., Espin, J., et al. (2013). Cryptococcus Neoformans Copper Detoxification Machinery Is Critical for Fungal Virulence. Cell Host Microbe 13 (3), 265-276. doi: 10.1016/ j.chom.2013.02.002

Ding, C., Festa, R. A., Sun, T. S., and Wang, Z. Y. (2014a). Iron and Copper as Virulence Modulators in Human Fungal Pathogens. Mol. Microbiol. 93 (1), 1023. doi: $10.1111 / \mathrm{mmi} .12653$

Ding, C., Hu, G., Jung, W. H., and Kronstad, J. W. (2014b). Essential Metals in Cryptococcus Neoformans: Acquisition and Regulation. Curr. Fungal Infect. Rep. 8 (2), 153-162. doi: 10.1007/s12281-014-0180-3

Ding, C., Yin, J., Tovar, E. M., Fitzpatrick, D. A., Higgins, D. G., and Thiele, D. J. (2011). The Copper Regulon of the Human Fungal Pathogen Cryptococcus Neoformans H99. Mol. Microbiol. 81 (6), 1560-1576. doi: 10.1111/j.13652958.2011.07794.x

Do, E., Park, S., Li, M. H., Wang, J. M., Ding, C., Kronstad, J. W., et al. (2018). The Mitochondrial ABC Transporter Atm1 Plays a Role in Iron Metabolism and Virulence in the Human Fungal Pathogen Cryptococcus Neoformans. Med. Mycol. 56 (4), 458-468. doi: 10.1093/mmy/myx073

Ecevit, I. Z., Clancy, C. J., Schmalfuss, I. M., and Nguyen, M. H. (2006). The Poor Prognosis of Central Nervous System Cryptococcosis Among Nonimmunosuppressed Patients: A Call for Better Disease Recognition and Evaluation of Adjuncts to Antifungal Therapy. Clin. Infect. Dis. 42 (10), 14431447. doi: 10.1086/503570

Eigenheer, R. A., Jin Lee, Y., Blumwald, E., Phinney, B. S., and Gelli, A. (2007). Extracellular Glycosylphosphatidylinositol-Anchored Mannoproteins and Proteases of Cryptococcus Neoformans. FEMS Yeast Res. 7 (4), 499-510. doi: 10.1111/j.1567-1364.2006.00198.x

Ene, I. V., Heilmann, C. J., Sorgo, A. G., Walker, L. A., de Koster, C. G., Munro, C. A., et al. (2012). Carbon Source-Induced Reprogramming of the Cell Wall Proteome and Secretome Modulates the Adherence and Drug Resistance of the Fungal Pathogen Candida Albicans. Proteomics 12 (21), 3164-3179. doi: 10.1002/pmic.201200228

Freire-Beneitez, V., Gourlay, S., Berman, J., and Buscaino, A. (2016). Sir2 Regulates Stability of Repetitive Domains Differentially in the Human Fungal Pathogen Candida Albicans. Nucleic Acids Res. 44 (19), 9166-9179. doi: 10.1093/nar/gkw594

Gautam, P., Mushahary, D., Hassan, W., Upadhyay, S. K., Madan, T., Sirdeshmukh, R., et al. (2016). In-Depth 2-DE Reference Map of Aspergillus Fumigatus and Its Proteomic Profiling on Exposure to Itraconazole. Med. Mycol. 54 (5), 524-536. doi: 10.1093/mmy/myv122

Geddes, J. M., Caza, M., Croll, D., Stoynov, N., Foster, L. J., and Kronstad, J. W. (2016). Analysis of the Protein Kinase A-Regulated Proteome of Cryptococcus Neoformans Identifies a Role for the Ubiquitin-Proteasome Pathway in Capsule Formation. mBio 7 (1), e01862-e01815. doi: 10.1128/ mBio.01862-15
Geddes, J. M., Croll, D., Caza, M., Stoynov, N., Foster, L. J., and Kronstad, J. W. (2015). Secretome Profiling of Cryptococcus Neoformans Reveals Regulation of a Subset of Virulence-Associated Proteins and Potential Biomarkers by Protein Kinase A. BMC Microbiol. 15, 206. doi: 10.1186/s12866-015-0532-3

Giusiano, G. (2020). The Trojan Horse Model in Paracoccidioides: A Fantastic Pathway to Survive Infecting Human Cells. Front. Cell Infect. Microbiol. 10, 605679. doi: 10.3389/fcimb.2020.605679

Hansakon, A., Mutthakalin, P., Ngamskulrungroj, P., Chayakulkeeree, M., and Angkasekwinai, P. (2019). Cryptococcus Neoformans and Cryptococcus Gattii Clinical Isolates From Thailand Display Diverse Phenotypic Interactions With Macrophages. Virulence 10 (1), 26-36. doi: 10.1080/21505594.2018.1556150

Heard, K. L., Hughes, S., Mughal, N., and Moore, L. S. P. (2020). COVID-19 and Fungal Superinfection. Lancet Microbe 1 (3), e107. doi: 10.1016/S2666-5247 (20)30065-3

Hole, C., and Wormley, F. L. Jr. (2016). Innate Host Defenses Against Cryptococcus Neoformans. J. Microbiol. 54 (3), 202-211. doi: 10.1007/ s12275-016-5625-7

Hoving, J. C., Brown, G. D., Gomez, B. L., Govender, N. P., Limper, A. H., May, R. C., et al. (2020). AIDS-Related Mycoses: Updated Progress and Future Priorities. Trends Microbiol. 28 (6), 425-428. doi: 10.1016/j.tim.2020.01.009

Huang, Q., and Figueiredo-Pereira, M. E. (2010). Ubiquitin/proteasome Pathway Impairment in Neurodegeneration: Therapeutic Implications. Apoptosis 15 (11), 1292-1311. doi: 10.1007/s10495-010-0466-z

Hu, G., Cheng, P. Y., Sham, A., Perfect, J. R., and Kronstad, J. W. (2008). Metabolic Adaptation in Cryptococcus Neoformans During Early Murine Pulmonary Infection. Mol. Microbiol. 69 (6), 1456-1475. doi: 10.1111/j.13652958.2008.06374.x

Hurtado, J. C., Castillo, P., Fernandes, F., Navarro, M., Lovane, L., Casas, I., et al. (2019). Mortality Due to Cryptococcus Neoformans and Cryptococcus Gattii in Low-Income Settings: An Autopsy Study. Sci. Rep. 9 (1), 7493. doi: 10.1038/ s41598-019-43941-w

Idnurm, A., Giles, S. S., Perfect, J. R., and Heitman, J. (2007). Peroxisome Function Regulates Growth on Glucose in the Basidiomycete Fungus Cryptococcus Neoformans. Eukaryot Cell 6 (1), 60-72. doi: 10.1128/EC.00214-06

Jacobsen, M. D., Beynon, R. J., Gethings, L. A., Claydon, A. J., Langridge, J. I., Vissers, J. P. C., et al. (2018). Specificity of the Osmotic Stress Response in Candida Albicans Highlighted by Quantitative Proteomics. Sci. Rep. 8 (1), 14492. doi: 10.1038/s41598-018-32792-6

Jung, C. H., Ro, S. H., Cao, J., Otto, N. M., and Kim, D. H. (2010). mTOR Regulation of Autophagy. FEBS Lett. 584 (7), 1287-1295. doi: 10.1016/ j.febslet.2010.01.017

Kawamata, T., Kamada, Y., Kabeya, Y., Sekito, T., and Ohsumi, Y. (2008). Organization of the Pre-Autophagosomal Structure Responsible for Autophagosome Formation. Mol. Biol. Cell 19 (5), 2039-2050. doi: 10.1091/ mbc.E07-10-1048

Khan, M. M., Ernst, O., Manes, N. P., Oyler, B. L., Fraser, I. D. C., Goodlett, D. R., et al. (2019). Multi-Omics Strategies Uncover Host-Pathogen Interactions. ACS Infect. Dis. 5 (4), 493-505. doi: 10.1021/acsinfecdis.9b00080

Krappmann, S., Jung, N., Medic, B., Busch, S., Prade, R. A., and Braus, G. H. (2006). The Aspergillus Nidulans F-Box Protein GrrA Links SCF Activity to Meiosis. Mol. Microbiol. 61 (1), 76-88. doi: 10.1111/j.1365-2958.2006.05215.x

Krassowski, M., Das, V., Sahu, S. K., and Misra, B. B. (2020). State of the Field in Multi-Omics Research: From Computational Needs to Data Mining and Sharing. Front. Genet. 11, 610798. doi: 10.3389/fgene.2020.610798

Kronstad, J. W., Attarian, R., Cadieux, B., Choi, J., D’Souza, C. A., Griffiths, E. J., et al. (2011). Expanding Fungal Pathogenesis: Cryptococcus Breaks Out of the Opportunistic Box. Nat. Rev. Microbiol. 9 (3), 193-203. doi: 10.1038/ nrmicro2522

Kronstad, J., Saikia, S., Nielson, E. D., Kretschmer, M., Jung, W., Hu, G., et al. (2012). Adaptation of Cryptococcus Neoformans to Mammalian Hosts: Integrated Regulation of Metabolism and Virulence. Eukaryot Cell 11 (2), 109-118. doi: 10.1128/EC.05273-11

Kumar, A., Ahmed, R., Singh, P. K., and Shukla, P. K. (2011). Identification of Virulence Factors and Diagnostic Markers Using Immunosecretome of Aspergillus Fumigatus. J. Proteomics 74 (7), 1104-1112. doi: 10.1016/ j.jprot.2011.04.004

Kurucz, V., Kruger, T., Antal, K., Dietl, A. M., Haas, H., Pocsi, I., et al. (2018). Additional Oxidative Stress Reroutes the Global Response of Aspergillus 
Fumigatus to Iron Depletion. BMC Genomics 19 (1), 357. doi: 10.1186/s12864018-4730-x

Lamoth, F., Juvvadi, P. R., Soderblom, E. J., Moseley, M. A., Asfaw, Y. G., and Steinbach, W. J. (2014). Identification of a Key Lysine Residue in Heat Shock Protein 90 Required for Azole and Echinocandin Resistance in Aspergillus Fumigatus. Antimicrob. Agents Chemother. 58 (4), 1889-1896. doi: 10.1128/ AAC.02286-13

Lee, I. H., and Finkel, T. (2009). Regulation of Autophagy by the P300 Acetyltransferase. J. Biol. Chem. 284 (10), 6322-6328. doi: 10.1074/ jbc.M807135200

Lee, D., Jang, E. H., Lee, M., Kim, S. W., Lee, Y., Lee, K. T., et al. (2019). Unraveling Melanin Biosynthesis and Signaling Networks in Cryptococcus Neoformans. mBio 10 (5), e02267-19. doi: 10.1128/mBio.02267-19

Lee, K. H., Kim, S. Y., Jung, J. H., and Kim, J. (2010). Proteomic Analysis of Hyphae-Specific Proteins That Are Expressed Differentially in Cakem1/ Cakem1 Mutant Strains of Candida Albicans. J. Microbiol. 48 (3), 365-371. doi: 10.1007/s12275-010-9155-4

Lee, I., Oh, J. H., Shwab, E. K., Dagenais, T. R., Andes, D., and Keller, N. P. (2009). HdaA, a Class 2 Histone Deacetylase of Aspergillus Fumigatus, Affects Germination and Secondary Metabolite Production. Fungal Genet. Biol. 46 (10), 782-790. doi: 10.1016/j.fgb.2009.06.007

Li, C., Li, Y., and Ding, C. (2019a). The Role of Copper Homeostasis at the HostPathogen Axis: From Bacteria to Fungi. Int. J. Mol. Sci. 20 (1), 175. doi: 10.3390/ijms20010175

Li, C., Li, Y. J., and Ding, C. (2019b). The Role of Copper Homeostasis at the HostPathogen Axis: From Bacteria to Fungi. Int. J. Mol. Sci. 20 (1), ARTN 175. doi: $10.3390 / \mathrm{ijms} 20010175$

Li, Y., Li, H., Sui, M., Li, M., Wang, J., Meng, Y., et al. (2019). Fungal Acetylome Comparative Analysis Identifies an Essential Role of Acetylation in Human Fungal Pathogen Virulence. Commun. Biol. 2, 154. doi: 10.1038/s42003-0190419-1

Li, H. L., Li, Y. J., Sun, T. S., Du, W., Li, C., Suo, C. H., et al. (2019). Unveil the Transcriptional Landscape at the Cryptococcus-Host Axis in Mice and Nonhuman Primates. PloS Neglect. Trop. Dis. 13 (7), e0007566. doi: 10.1371/ journal.pntd.0007566

Li, H., Li, Y., Sun, T., Du, W., Zhang, Z., Li, D., et al. (2020). Integrative Proteome and Acetylome Analyses of Murine Responses to Cryptococcus Neoformans Infection. Front. Microbiol. 11, 575. doi: 10.3389/fmicb.2020.00575

Liu, T. B., Wang, Y., Stukes, S., Chen, Q., Casadevall, A., and Xue, C. (2011). The F-Box Protein Fbp1 Regulates Sexual Reproduction and Virulence in Cryptococcus Neoformans. Eukaryot Cell 10 (6), 791-802. doi: 10.1128/ EC.00004-11

Liu, T. B., and Xue, C. (2014). Fbp1-Mediated Ubiquitin-Proteasome Pathway Controls Cryptococcus Neoformans Virulence by Regulating Fungal Intracellular Growth in Macrophages. Infect. Immun. 82 (2), 557-568. doi: 10.1128/IAI.00994-13

Lu, Y., Su, C., and Liu, H. (2012). A GATA Transcription Factor Recruits Hdal in Response to Reduced Tor1 Signaling to Establish a Hyphal Chromatin State in Candida Albicans. PloS Pathog. 8 (4), e1002663. doi: 10.1371/ journal.ppat.1002663

Machata, S., Muller, M. M., Lehmann, R., Sieber, P., Panagiotou, G., Carvalho, A., et al. (2020). Proteome Analysis of Bronchoalveolar Lavage Fluids Reveals Host and Fungal Proteins Highly Expressed During Invasive Pulmonary Aspergillosis in Mice and Humans. Virulence 11 (1), 1337-1351. doi: $10.1080 / 21505594.2020 .1824960$

Manfiolli, A. O., de Castro, P. A., Dos Reis, T. F., Dolan, S., Doyle, S., Jones, G., et al. (2017). Aspergillus Fumigatus Protein Phosphatase PpzA Is Involved in Iron Assimilation, Secondary Metabolite Production, and Virulence. Cell Microbiol. 19 (12). doi: 10.1111/cmi.12770

Margalit, A., Kavanagh, K., and Carolan, J. C. (2020). Characterization of the Proteomic Response of A549 Cells Following Sequential Exposure to Aspergillus Fumigatus and Pseudomonas Aeruginosa. J. Proteome Res. 19 (1), 279-291. doi: 10.1021/acs.jproteome.9b00520

Martinez Barrera, S., Byrum, S., Mackintosh, S. G., and Kozubowski, L. (2020). Registered Report Protocol: Quantitative Analysis of Septin Cdc10-Associated Proteome in Cryptococcus Neoformans. PloS One 15 (12), e0242381. doi: 10.1371/journal.pone.0242381
Martins, L. M., de Andrade, H. M., Vainstein, M. H., Wanke, B., Schrank, A., Balaguez, C. B., et al. (2013). Immunoproteomics and Immunoinformatics Analysis of Cryptococcus Gattii: Novel Candidate Antigens for Diagnosis. Future Microbiol. 8 (4), 549-563. doi: 10.2217/fmb.13.22

Mattos, E. C., Palmisano, G., and Goldman, G. H. (2020a). Phosphoproteomics of Aspergillus Fumigatus Exposed to the Antifungal Drug Caspofungin. mSphere 5 (3), e00365-20. doi: 10.1128/mSphere.00365-20

Mattos, E. C., Silva, L. P., Valero, C., de Castro, P. A., Dos Reis, T. F., Ribeiro, L. F. C., et al. (2020b). The Aspergillus Fumigatus Phosphoproteome Reveals Roles of High-Osmolarity Glycerol Mitogen-Activated Protein Kinases in Promoting Cell Wall Damage and Caspofungin Tolerance. mBio 11 (1), e02962-19. doi: 10.1128/mBio.02962-19

Moloney, N. M., Owens, R. A., Meleady, P., Henry, M., Dolan, S. K., Mulvihill, E., et al. (2016). The Iron-Responsive Microsomal Proteome of Aspergillus Fumigatus. J. Proteomics 136, 99-111. doi: 10.1016/j.jprot.2015.12.025

Mukaremera, L., Lee, K. K., Wagener, J., Wiesner, D. L., Gow, N. A. R., and Nielsen, K. (2018). Titan Cell Production in Cryptococcus Neoformans Reshapes the Cell Wall and Capsule Composition During Infection. Cell Surf 1, 15-24. doi: 10.1016/j.tcsw.2017.12.001

Mulvihill, E. D., Moloney, N. M., Owens, R. A., Dolan, S. K., Russell, L., and Doyle, S. (2017). Functional Investigation of Iron-Responsive Microsomal Proteins, Including MirC, in Aspergillus Fumigatus. Front. Microbiol. 8, 418. doi: $10.3389 /$ fmicb.2017.00418

Muthamil, S., Prasath, K. G., Priya, A., Precilla, P., and Pandian, S. K. (2020). Global Proteomic Analysis Deciphers the Mechanism of Action of Plant Derived Oleic Acid Against Candida Albicans Virulence and Biofilm Formation. Sci. Rep. 10 (1), 5113. doi: 10.1038/s41598-020-61918-y

Nelson, B. N., Hawkins, A. N., and Wozniak, K. L. (2020). Pulmonary Macrophage and Dendritic Cell Responses to Cryptococcus Neoformans. Front. Cell Infect. Microbiol. 10, 37. doi: 10.3389/fcimb.2020.00037

Nijholt, D. A., De Kimpe, L., Elfrink, H. L., Hoozemans, J. J., and Scheper, W. (2011). Removing Protein Aggregates: The Role of Proteolysis in Neurodegeneration. Curr. Med. Chem. 18 (16), 2459-2476. doi: 10.2174/ 092986711795843236

Olson, G. M., Fox, D. S., Wang, P., Alspaugh, J. A., and Buchanan, K. L. (2007). Role of Protein O-Mannosyltransferase Pmt4 in the Morphogenesis and Virulence of Cryptococcus Neoformans. Eukaryot Cell 6 (2), 222-234. doi: 10.1128/EC.00182-06

Pandey, A., Ding, S. L., Qin, Q. M., Gupta, R., Gomez, G., Lin, F., et al. (2017). Global Reprogramming of Host Kinase Signaling in Response to Fungal Infection. Cell Host Microbe 21 (5), 637-649.e636. doi: 10.1016/ j.chom.2017.04.008

Paquette, M., El-Houjeiri, L., and Pause, A. (2018). mTOR Pathways in Cancer and Autophagy. Cancers (Basel) 10 (1), 18. doi: 10.3390/cancers10010018

Pasquier, G., Bounhiol, A., Robert Gangneux, F., Zahar, J. R., Gangneux, J. P., Novara, A., et al. (2021). A Review of Significance of Aspergillus Detection in Airways of ICU COVID-19 Patients. Mycoses 64 (9), 980-988. doi: 10.1111/myc.13341

Prasath, K. G., Sethupathy, S., and Pandian, S. K. (2019). Proteomic Analysis Uncovers the Modulation of Ergosterol, Sphingolipid and Oxidative Stress Pathway by Myristic Acid Impeding Biofilm and Virulence in Candida Albicans. J. Proteomics 208:103503. doi: 10.1016/j.jprot.2019.103503

Rajasingham, R., Smith, R. M., Park, B. J., Jarvis, J. N., Govender, N. P., Chiller, T. M., et al. (2017). Global Burden of Disease of HIV-Associated Cryptococcal Meningitis: An Updated Analysis. Lancet Infect. Dis. 17 (8), 873-881. doi: 10.1016/S1473-3099(17)30243-8

Rawson, T. M., Wilson, R. C., and Holmes, A. (2021). Understanding the Role of Bacterial and Fungal Infection in COVID-19. Clin. Microbiol. Infect. 27 (1), 911. doi: 10.1016/j.cmi.2020.09.025

Reales-Calderon, J. A., Aguilera-Montilla, N., Corbi, A. L., Molero, G., and Gil, C. (2014). Proteomic Characterization of Human Proinflammatory M1 and AntiInflammatory M2 Macrophages and Their Response to Candida Albicans. Proteomics 14 (12), 1503-1518. doi: 10.1002/pmic.201300508

Reales-Calderon, J. A., Sylvester, M., Strijbis, K., Jensen, O. N., Nombela, C., Molero, G., et al. (2013). Candida Albicans Induces Pro-Inflammatory and Anti-Apoptotic Signals in Macrophages as Revealed by Quantitative Proteomics and Phosphoproteomics. J. Proteomics 91, 106-135. doi: 10.1016/ j.jprot.2013.06.026 
Rodrigues, M. L., Nakayasu, E. S., Oliveira, D. L., Nimrichter, L., Nosanchuk, J. D., Almeida, I. C., et al. (2008). Extracellular Vesicles Produced by Cryptococcus Neoformans Contain Protein Components Associated With Virulence. Eukaryot Cell 7 (1), 58-67. doi: 10.1128/EC.00370-07

Rohatgi, S., and Pirofski, L. A. (2015). Host Immunity to Cryptococcus Neoformans. Future Microbiol. 10 (4), 565-581. doi: 10.2217/fmb.14.132

Rosa, R. L., Berger, M., Santi, L., Driemeier, D., Barros Terraciano, P., Campos, A. R., et al. (2019). Proteomics of Rat Lungs Infected by Cryptococcus Gattii Reveals a Potential Warburg-Like Effect. J. Proteome Res. 18 (11), 3885-3895. doi: 10.1021/acs.jproteome.9b00326

Saikia, S., Oliveira, D., Hu, G., and Kronstad, J. (2014). Role of Ferric Reductases in Iron Acquisition and Virulence in the Fungal Pathogen Cryptococcus Neoformans. Infect. Immun. 82 (2), 839-850. doi: 10.1128/IAI.01357-13

Samanovic, M. I., Ding, C., Thiele, D. J., and Darwin, K. H. (2012). Copper in Microbial Pathogenesis: Meddling With the Metal. Cell Host Microbe 11 (2), 106-115. doi: 10.1016/j.chom.2012.01.009

Samaranayake, Y. H., Cheung, B. P. K., Wang, Y., Yau, J. Y. Y., Yeung, K. W. S., and Samaranayake, L. P. (2013). Fluconazole Resistance in Candida Glabrata Is Associated With Increased Bud Formation and Metallothionein Production. J. Med. Microbiol. 62 (Pt 2), 303-318. doi: 10.1099/jmm.0.044123-0

Santiago-Tirado, F. H., and Doering, T. L. (2017). False Friends: Phagocytes as Trojan Horses in Microbial Brain Infections. PloS Pathog. 13 (12), e1006680. doi: 10.1371 /journal.ppat.1006680

Santiago-Tirado, F. H., Onken, M. D., Cooper, J. A., Klein, R. S., and Doering, T. L. (2017). Trojan Horse Transit Contributes to Blood-Brain Barrier Crossing of a Eukaryotic Pathogen. mBio 8 (1), e02183-16. doi: 10.1128/mBio.02183-16

Santi, L., Beys-da-Silva, W. O., Berger, M., Calzolari, D., Guimaraes, J. A., Moresco, J. J., et al. (2014). Proteomic Profile of Cryptococcus Neoformans Biofilm Reveals Changes in Metabolic Processes. J. Proteome Res. 13 (3), 15451559. doi: 10.1021/pr401075f

Scherer, A. K., Blair, B. A., Park, J., Seman, B. G., Kelley, J. B., and Wheeler, R. T. (2020). Redundant Trojan Horse and Endothelial-Circulatory Mechanisms for Host-Mediated Spread of Candida Albicans Yeast. PloS Pathog. 16 (8), e1008414. doi: 10.1371/journal.ppat.1008414

Schmidt, H., Vlaic, S., Kruger, T., Schmidt, F., Balkenhol, J., Dandekar, T., et al. (2018). Proteomics of Aspergillus Fumigatus Conidia-Containing Phagolysosomes Identifies Processes Governing Immune Evasion. Mol. Cell Proteomics 17 (6), 1084-1096. doi: 10.1074/mcp.RA117.000069

Selvan, L. D., Renuse, S., Kaviyil, J. E., Sharma, J., Pinto, S. M., Yelamanchi, S. D., et al. (2014). Phosphoproteome of Cryptococcus Neoformans. J. Proteomics 97, 287-295. doi: 10.1016/j.jprot.2013.06.029

Seoane, P. I., Taylor-Smith, L. M., Stirling, D., Bell, L. C. K., Noursadeghi, M., Bailey, D., et al. (2020). Viral Infection Triggers Interferon-Induced Expulsion of Live Cryptococcus Neoformans by Macrophages. PloS Pathog. 16 (2), e1008240. doi: 10.1371/journal.ppat.1008240

Sheehan, G., Nagl, M., and Kavanagh, K. (2019). Exposure to N-Chlorotaurine Induces Oxidative Stress Responses in Aspergillus Fumigatus. J. Med. Microbiol. 68 (2), 279-288. doi: 10.1099/jmm.0.000900

Shemesh, E., Hanf, B., Hagag, S., Attias, S., Shadkchan, Y., Fichtman, B., et al. (2017). Phenotypic and Proteomic Analysis of the Aspergillus Fumigatus DeltaPrtT, DeltaXprG and DeltaXprG/DeltaPrtT Protease-Deficient Mutants. Front. Microbiol. 8, 2490. doi: 10.3389/fmicb.2017.02490

Shliapina, V. L., Yurtaeva, S. V., Rubtsova, M. P., and Dontsova, O. A. (2021). At the Crossroads: Mechanisms of Apoptosis and Autophagy in Cell Life and Death. Acta Naturae 13 (2), 106-115. doi: 10.32607/actanaturae.11208

Silva, L. P., Frawley, D., Assis, L. J., Tierney, C., Fleming, A. B., Bayram, O., et al. (2020). Putative Membrane Receptors Contribute to Activation and Efficient Signaling of Mitogen-Activated Protein Kinase Cascades During Adaptation of Aspergillus Fumigatus to Different Stressors and Carbon Sources. mSphere 5 (5), e00818-20. doi: 10.1128/mSphere.00818-20

Sim, S. Y., Choi, Y. R., Lee, J. H., Lim, J. M., Lee, S. E., Kim, K. P., et al. (2019). InDepth Proteomic Analysis of Human Bronchoalveolar Lavage Fluid Toward the Biomarker Discovery for Lung Cancers. Proteomics Clin. Appl. 13 (5), e1900028. doi: 10.1002/prca.201900028

Singh, S., Verma, N., Kanaujia, R., Chakrabarti, A., and Rudramurthy, S. M. (2021). Mortality in Critically Ill Patients With Coronavirus Disease 2019Associated Pulmonary Aspergillosis: A Systematic Review and Meta-Analysis. Mycoses 64 (9), 1015-1027. doi: 10.1111/myc.13328
Song, M., Greenbaum, J., Luttrell, J. T., Zhou, W., Wu, C., Shen, H., et al. (2020). A Review of Integrative Imputation for Multi-Omics Datasets. Front. Genet. 11, 570255. doi: 10.3389/fgene.2020.570255

Song, G., Liang, G., and Liu, W. (2020). Fungal Co-Infections Associated With Global COVID-19 Pandemic: A Clinical and Diagnostic Perspective From China. Mycopathologia 185 (4), 599-606. doi: 10.1007/s11046-020-00462-9

Sorrell, T. C., Juillard, P. G., Djordjevic, J. T., Kaufman-Francis, K., Dietmann, A., Milonig, A., et al. (2016). Cryptococcal Transmigration Across a Model Brain Blood-Barrier: Evidence of the Trojan Horse Mechanism and Differences Between Cryptococcus Neoformans Var. Grubii Strain H99 and Cryptococcus Gattii Strain R265. Microbes Infect. 18 (1), 57-67. doi: 10.1016/j.micinf.2015.08.017

Stone, N. R., Rhodes, J., Fisher, M. C., Mfinanga, S., Kivuyo, S., Rugemalila, J., et al. (2019). Dynamic Ploidy Changes Drive Fluconazole Resistance in Human Cryptococcal Meningitis. J. Clin. Invest. 129 (3), 999-1014. doi: 10.1172/ JCI124516

Sun, T. S., Ju, X., Gao, H. L., Wang, T., Thiele, D. J., Li, J. Y., et al. (2014). Reciprocal Functions of Cryptococcus Neoformans Copper Homeostasis Machinery During Pulmonary Infection and Meningoencephalitis. Nat. Commun. 5, 5550. doi: 10.1038/ncomms6550

Sun, T., Li, Y., Li, Y., Li, H., Gong, Y., Wu, J., et al. (2021). Proteomic Analysis of Copper Toxicity in Human Fungal Pathogen Cryptococcus Neoformans. Front. Cell. Infect. Microbiol. 11, 662404. doi: 10.3389/fcimb.2021.662404

Sun, D., Sun, P., Li, H., Zhang, M., Liu, G., Strickland, A. B., et al. (2019). Fungal Dissemination Is Limited by Liver Macrophage Filtration of the Blood. Nat. Commun. 10 (1), 4566. doi: 10.1038/s41467-019-12381-5

Suo, C. H., Ma, L. J., Li, H. L., Sun, J. F., Li, C., Lin, M. H., et al. (2018). Investigation of Cryptococcus Neoformans Magnesium Transporters Reveals Important Role of Vacuolar Magnesium Transporter in Regulating Fungal Virulence Factors. Microbiologyopen 7 (3), e00564. doi: 10.1002/mbo3.564

Tarrand, J. J., Han, X. Y., Kontoyiannis, D. P., and May, G. S. (2005). Aspergillus Hyphae in Infected Tissue: Evidence of Physiologic Adaptation and Effect on Culture Recovery. J. Clin. Microbiol. 43 (1), 382-386. doi: 10.1128/ JCM.43.1.382-386.2005

Thak, E. J., Lee, S. B., Xu-Vanpala, S., Lee, D. J., Chung, S. Y., Bahn, Y. S., et al. (2020). Core N-Glycan Structures Are Critical for the Pathogenicity of Cryptococcus Neoformans by Modulating Host Cell Death. mBio 11 (3), e00711-20. doi: 10.1128/mBio.00711-20

Thomas, D. P., Lopez-Ribot, J. L., and Lee, S. A. (2009). A Proteomic Analysis of Secretory Proteins of a Pre-Vacuolar Mutant of Candida Albicans. J. Proteomics 73 (2), 342-351. doi: 10.1016/j.jprot.2009.10.003

Toor, A., Culibrk, L., Singhera, G. K., Moon, K. M., Prudova, A., Foster, L. J., et al. (2018). Transcriptomic and Proteomic Host Response to Aspergillus Fumigatus Conidia in an Air-Liquid Interface Model of Human Bronchial Epithelium. PloS One 13 (12), e0209652. doi: 10.1371/journal.pone.0209652

Vargas, G., Rocha, J. D., Oliveira, D. L., Albuquerque, P. C., Frases, S., Santos, S. S., et al. (2015). Compositional and Immunobiological Analyses of Extracellular Vesicles Released by Candida Albicans. Cell Microbiol. 17 (3), 389-407. doi: $10.1111 / \mathrm{cmi} .12374$

Vaz, C., Reales-Calderon, J. A., Pitarch, A., Vellosillo, P., Trevisan, M., Hernaez, M. L., et al. (2019). Enrichment of ATP Binding Proteins Unveils Proteomic Alterations in Human Macrophage Cell Death, Inflammatory Response, and Protein Synthesis After Interaction With Candida Albicans. J. Proteome Res. 18 (5), 2139-2159. doi: 10.1021/acs.jproteome.9b00032

Virginio, E. D., Kubitschek-Barreira, P. H., Batista, M. V., Schirmer, M. R., Abdelhay, E., Shikanai-Yasuda, M. A., et al. (2014). Immunoproteome of Aspergillus Fumigatus Using Sera of Patients With Invasive Aspergillosis. Int. J. Mol. Sci. 15 (8), 14505-14530. doi: 10.3390/ijms150814505

Vodisch, M., Scherlach, K., Winkler, R., Hertweck, C., Braun, H. P., Roth, M., et al. (2011). Analysis of the Aspergillus Fumigatus Proteome Reveals Metabolic Changes and the Activation of the Pseurotin A Biosynthesis Gene Cluster in Response to Hypoxia. J. Proteome Res. 10 (5), 2508-2524. doi: 10.1021/ pr1012812

Vu, K., Garcia, J. A., and Gelli, A. (2019). Cryptococcal Meningitis and AntiVirulence Therapeutic Strategies. Front. Microbiol. 10, 353. doi: 10.3389/ fmicb.2019.00353

Vu, K., Tham, R., Uhrig, J. P., Thompson, G. R.3rd, Na Pombejra, S., Jamklang, M., et al. (2014). Invasion of the Central Nervous System by Cryptococcus 
Neoformans Requires a Secreted Fungal Metalloprotease. mBio 5 (3), e01101e01114. doi: 10.1128/mBio.01101-14

Wang, L., Zhai, B., and Lin, X. (2012). The Link Between Morphotype Transition and Virulence in Cryptococcus Neoformans. PloS Pathog. 8 (6), e1002765. doi: 10.1371/journal.ppat.1002765

Wang, Y., and Zhang, H. (2019). Regulation of Autophagy by mTOR Signaling Pathway. Adv. Exp. Med. Biol. 1206, 67-83. doi: 10.1007/978-981-15-0602-4_3

Warn, P. A., Sharp, A., Guinea, J., and Denning, D. W. (2004). Effect of Hypoxic Conditions on In Vitro Susceptibility Testing of Amphotericin B, Itraconazole and Micafungin Against Aspergillus and Candida. J. Antimicrob. Chemother. 53 (5), 743-749. doi: 10.1093/jac/dkh153

Willger, S. D., Puttikamonkul, S., Kim, K. H., Burritt, J. B., Grahl, N., Metzler, L. J., et al. (2008). A Sterol-Regulatory Element Binding Protein Is Required for Cell Polarity, Hypoxia Adaptation, Azole Drug Resistance, and Virulence in Aspergillus Fumigatus. PloS Pathog. 4 (11), e1000200. doi: 10.1371/ journal.ppat. 1000200

Wolf, J. M., Espadas, J., Luque-Garcia, J., Reynolds, T., and Casadevall, A. (2015). Lipid Biosynthetic Genes Affect Candida Albicans Extracellular Vesicle Morphology, Cargo, and Immunostimulatory Properties. Eukaryot Cell 14 (8), 745-754. doi: 10.1128/EC.00054-15

Wolf, J. M., Espadas-Moreno, J., Luque-Garcia, J. L., and Casadevall, A. (2014). Interaction of Cryptococcus Neoformans Extracellular Vesicles With the Cell Wall. Eukaryot Cell 13 (12), 1484-1493. doi: 10.1128/EC.00111-14

Wurtele, H., Tsao, S., Lepine, G., Mullick, A., Tremblay, J., Drogaris, P., et al. (2010). Modulation of Histone H3 Lysine 56 Acetylation as an Antifungal Therapeutic Strategy. Nat. Med. 16 (7), 774-780. doi: 10.1038/nm.2175

Xu, Y., Wang, Y., Yan, L., Liang, R. M., Dai, B. D., Tang, R. J., et al. (2009). Proteomic Analysis Reveals a Synergistic Mechanism of Fluconazole and Berberine Against Fluconazole-Resistant Candida Albicans: Endogenous ROS Augmentation. J. Proteome Res. 8 (11), 5296-5304. doi: 10.1021/pr9005074

Yi, C., Ma, M., Ran, L., Zheng, J., Tong, J., Zhu, J., et al. (2012). Function and Molecular Mechanism of Acetylation in Autophagy Regulation. Science 336 (6080), 474-477. doi: 10.1126/science.1216990

Yoon, H. A., Felsen, U., Wang, T., and Pirofski, L. A. (2020). Cryptococcus Neoformans Infection in Human Immunodeficiency Virus (HIV)-Infected and HIV-Uninfected Patients at an Inner-City Tertiary Care Hospital in the Bronx. Med. Mycol. 58 (4), 434-443. doi: 10.1093/mmy/myz082

Young, M., Macias, S., Thomas, D., and Wormley, F. L.Jr. (2009). A ProteomicBased Approach for the Identification of Immunodominant Cryptococcus
Neoformans Proteins. Proteomics 9 (9), 2578-2588. doi: 10.1002/ pmic. 200800713

Zamith-Miranda, D., Heyman, H. M., Cleare, L. G., Couvillion, S. P., Clair, G. C., Bredeweg, E. L., et al. (2019). Multi-Omics Signature of Candida Auris, an Emerging and Multidrug-Resistant Pathogen. mSystems 4 (4), e00257-19. doi: 10.1128/mSystems.00257-19

Zhang, Y., Fan, J., Ye, J., and Lu, L. (2021). The Fungal-Specific Histone Acetyltransferase Rtt109 Regulates Development, DNA Damage Response, and Virulence in Aspergillus Fumigatus. Mol. Microbiol. 115 (6), 1191-1206. doi: $10.1111 / \mathrm{mmi} .14665$

Zhang, L., Zhang, K. M., Li, H., Coelho, C., Goncalves, D. D., Fu, M. S., et al. (2021). Cryptococcus Neoformans-Infected Macrophages Release Proinflammatory Extracellular Vesicles: Insight Into Their Components by Multi-Omics. Mbio 12 (2), e00279-21. doi: 10.1128/mBio.00279-21

Zhou, X., Song, N., Li, D., Li, X., and Liu, W. (2021). Systematic Analysis of the Lysine Crotonylome and Multiple Posttranslational Modification Analysis (Acetylation, Succinylation, and Crotonylation) in Candida Albicans. mSystems 6 (1), e01316-20. doi: 10.1128/mSystems.01316-20

Zohbi, R., Wex, B., and Khalaf, R. A. (2014). Comparative Proteomic Analysis of a Candida Albicans DSE1 Mutant Under Filamentous and Non-Filamentous Conditions. Yeast 31 (11), 441-448. doi: 10.1002/yea.3039

Conflict of Interest: The authors declare that the research was conducted in the absence of any commercial or financial relationships that could be construed as a potential conflict of interest.

Publisher's Note: All claims expressed in this article are solely those of the authors and do not necessarily represent those of their affiliated organizations, or those of the publisher, the editors and the reviewers. Any product that may be evaluated in this article, or claim that may be made by its manufacturer, is not guaranteed or endorsed by the publisher.

Copyright $\odot 2021 \mathrm{Li}, \mathrm{Li}$, Sun and Ding. This is an open-access article distributed under the terms of the Creative Commons Attribution License (CC BY). The use, distribution or reproduction in other forums is permitted, provided the original author $(s)$ and the copyright owner(s) are credited and that the original publication in this journal is cited, in accordance with accepted academic practice. No use, distribution or reproduction is permitted which does not comply with these terms. 